\title{
Relationship between muscle strength and motor function in Duchenne muscular dystrophy
}

\author{
Relação entre força muscular e função motora na distrofia muscular de Duchenne \\ Milene F. Nunes', Michele E. Hukuda', Francis M. Favero², Acary B. Oliveira², Mariana C. Voos ${ }^{1}$, Fátima A. Caromano'
}

\begin{abstract}
Measuring muscle strength and motor function is part of Duchenne muscular dystrophy (DMD) assessment. However, the relationship between these variables is controversial. Objective: To investigate the relationship between muscle strength and motor function and between these variables and age. Method: Muscle strength was measured by Medical Research Council (MRC) scale and motor function, by Motor Function Measure (MFM), in 40 non-ambulatory patients. Spearman tests investigated the relationships between muscle strength, motor function and age. Results: Total MRC and MFM scores were strongly related to each other $(r=0.94 ; p<0.001)$, but not to age ( $r=-0.19$, $r=-0.31$, respectively; $p>0.05$ ). Strong and moderate relationships between partial muscle strength and motor function scores were found. Higher correlation coefficients were found between total scores and Dimensions 2 (axial/ proximal control) and 3 (distal control) of MFM. Conclusion: Muscle strength and motor function are strongly correlated and seem to decrease proportionally in DMD.
\end{abstract}

Keywords: muscular dystrophy, Duchenne; motor activity; motor skills; muscle strength; Statistics, Nonparametric.

\section{RESUMO}

Mensurar força muscular e função motora é parte da avaliação em distrofia muscular de Duchenne (DMD). A relação entre essas variáveis é controversa. Objetivo: Investigar a relação entre força muscular, função motora e idade. Método: Força muscular foi medida pela Medical Research Council (MRC), e função motora pela escala Medida da Função Motora (MFM), em 40 pacientes cadeirantes. Teste de Spearman investigou as relações entre força muscular, função motora e idade. Resultados: 0 escore total da escala MRC e da MFM foram fortemente relacionados entre si $(r=0,94 ; p<0,001)$, mas não com a idade $(r=-0,19 ; r=-0,31$, respectivamente; $p>0,05)$. Foram encontradas correlações fortes e moderadas entre os escores parciais de força muscular e função motora. As relações mais fortes ocorreram entre os escores totais, Dimensão 2 (controle axial/proximal) e 3 (controle distal) da escala MFM. Conclusão: Força muscular e função motora estão fortemente correlacionadas e parecem diminuir proporcionalmente na DMD.

Palavras-chave: distrofia muscular de Duchenne; atividade motora; destreza motora; força muscular; estatísticas não paramétricas.

In the last years, the importance of accurate, reliable and sensitive outcome measures in patients with Duchenne muscular dystrophy (DMD) has been outlined ${ }^{1,2,3}$. Motor function is, currently, the main outcome measure (e.g. Motor Function Measure, $\mathrm{MFM}^{2,4,5}$, six-minute walking test ${ }^{6}$ and North Star ambulatory assessment ${ }^{7,8}$ ). However, motor function scores can be complemented by clinical measures, such as muscle strength, evaluated by the Medical Research Council scale (MRC) $)^{9,10,11,12,13}$, to provide more detailed monitoring of disease progression ${ }^{2,3}$.

In $\mathrm{DMD}$, muscle strength is assessed to describe weakness topography and disease progression rate. This knowledge contributes to the rationale for therapeutic interventions, e.g. to test treatment (medication, orthoses) efficacy, facing DMD progression $^{14}$. MRC involves manual muscle testing, which is a procedure to evaluate the strength of muscle groups, based on the performance of a movement, in relation to the manual resistance and gravity force $\mathrm{e}^{9,10,11,12,13}$.

The ability to overcome the maximum resistance applied within the possible range of motion (considering that some patients have joint and muscle retractions) is scored as 5 . The ability to overcome partial resistance is scored as 4 . The ability to overcome gravity within the possible range of motion is scored as 3 . The ability to move partially, with lower amplitude than the possible passive range of motion is scored as 2 . The ability to contract muscles, without joint movement, is scored as 1 . The absence of muscle contraction is scored as zero. Therefore, MRC ranges from 5 to 0 , with 5 being normal strength and 0 being no observable muscle contraction ${ }^{9,10,11,12,13}$.

\footnotetext{
${ }^{1}$ Universidade de São Paulo, Faculdade de Medicina, Departamento de Fisioterapia, Fonoaudiologia e Terapia Ocupacional, São Paulo SP, Brasil; ${ }^{2}$ Universidade Federal de São Paulo, Faculdade de Medicina, Departamento de Neurologia, São Paulo SP, Brasil.

Correspondence: Francis Meire Favero; Faculdade de Medicina, UNIFESP, Departamento de Neurologia / Neurocirurgia; Rua Botucatu, 740; 04021-001 São Paulo SP, Brasil; E-mail: ffave.nexp@latoneuro.com.br

Conflict of interest: There is no conflict of interest to declare.

Received 25 March 2015; Received in final form 10 Aug 2015; Accepted 05 May 2016.
} 
The validity of MRC has been determined in literature $^{9,10,11,12}$. However, some studies ${ }^{11,14,15}$ considered the scale subjective and, therefore, therapist-dependent. This occurred because MRC score is provided by the therapists' clinical visual and manual perception of movement ${ }^{15}$. For instance, the amount of manual resistance applied to differ score 4 (moderate resistance) from 5 (strong resistance) is subjective and may differ among therapists.

MRC also allows the calculation of partial scores. The proximal upper limb score involves shoulder flexors, extensors, abductors, adductors, internal and external rotators strength. The distal upper limb score involves elbow flexors and extensors, supinators and pronators and wrist flexors and extensors strength. The proximal lower limb score includes hip flexors, extensors, abductors, adductors, internal and external rotators strength. The distal lower limb score includes knee flexors and extensors and ankle dorsiflexors, plantar flexors, invertors and eversors strength ${ }^{9}$.

MFM was validated in Portuguese ${ }^{5}$. It has high reliability and responsiveness ${ }^{2,4,5}$. It assesses motor function and is applicable to both ambulatory and wheelchair-dependent patients. Dimension 1 assesses standing position and transfers, Dimension 2 evaluates axial and proximal motor function and Dimension 3 evaluates distal motor function. The information provided by functional scales, e.g. MFM, is fundamental to assess and follow patients with DMD.

However, the primary problem in DMD, which disrupts motor function, is muscle strength. The muscle contractile property is reduced, due to the deterioration occurred in the absence of dystrophin. Despite having some muscle strength tests (head, hip and ankle flexion against gravity), the MFM does not employ manual resistance, nor focuses on specific muscle groups contraction, because the main scope is measuring function.

The decrease in functional dependence (detected by $\mathrm{MFM}^{2,4,5}$, six-minute walking test ${ }^{6}$ and/or North Star ambulatory assessment ${ }^{7,8}$ ) has been associated to the reduction of muscle mass ${ }^{16}$ and muscle strength ${ }^{17}$. However, the relationship between muscle strength and motor function in patients with DMD has not been quantified, nor discussed in the literature. The studies that investigated the relationship between muscle strength and motor function included heterogeneous populations with neuromuscular diseases ${ }^{12,18}$, assessed few muscle groups ${ }^{1,12,19}$ and/or did not include all the domains of $\mathrm{MFM}^{19}$.

Besides, the findings have been contradictory. Vuillerot et al. $^{2}$ stated that muscle strength and motor function were not related because many other factors, e.g. range of motion and pain, influenced motor control. Conversely, Scott et al. ${ }^{9}$ reported that the relationship between muscle strength and motor function differed among age groups and level of wheelchair dependence. They established patterns of DMD progression, which could serve as references. They followed 61 patients with DMD for three years and assessed the total muscle strength, with MRC scale, and the motor function, evaluated by Hammersmith Motor Assessment Scale (HMAS), a scale with 20 functional activities. The decline of muscle strength was related to age increase and motor function loss 9 .

The knowledge of how muscle strength (including the total MRC score and the upper and lower limbs partial scores) and motor function (including the total MFM score and the Dimensions scores) are related may be helpful for researchers and therapists in data interpreting and clinical decision-making. Our primary aim was to investigate the relationship between muscle strength, assessed by the total and partial scores of MRC and motor function, assessed by the total and partial scores of MFM in patients with DMD. Our secondary aim was to investigate the relationship between these variables and age.

\section{METHODS}

\section{Subjects}

This is a cross-sectional study, approved by the Research Ethics Committee of Universidade Federal de São Paulo. It included 40 non-ambulatory patients, from 12 to 30 years of age, classified from 7 to 9 with the Vignos scale ${ }^{20}$, receiving multidisciplinary assistance at Brazilian Association of Muscular Dystrophy. The diagnosis of DMD was confirmed by DNA analysis and/or muscular biopsy with histochemical or immunohistochemical study). Corticosteroid therapy was prescribed according to the international consensus ${ }^{21}$. All participating therapists had a minimum of two years experience with patients with DMD and specific training on the scales used.

Muscle strength was assessed with the MRC scale and motor function was assessed with the MFM, by physiotherapists from the Brazilian Association of Muscular Dystrophy, who had two or more years practice with assessment and treatment of patients with DMD. Patients unable to understand verbal commands or presenting any additional clinical or motor impairment that contraindicated the assessment with MRC scale and MFM were excluded. The order between muscle strength and motor function assessment protocol and the therapists assessing scales and patients were randomized.

\section{Procedures}

\section{Assessment with MRC and MFM}

MRC tests muscle strength by employing manual resistance, with the patient lying on dorsal, ventral, lateral decubitus and on sitting position. Both left and right sides are tested, to minimize dominance influences and possible asymmetrical involvement of the muscle groups. Shoulder flexors, extensors, abductors, adductors, internal and external rotators; elbow flexors and extensors, supinators, pronators; wrist flexors and extensors; hip flexors, extensors, abductors, adductors, internal and external rotators; knee flexors and extensors; ankle dorsiflexors, plantar flexors, 
invertors and eversors are evaluated. The best score obtained (comparing both sides) is registered.

The muscle strength is graded from zero to five. Zero means no contraction; one indicates flicker or trace of contraction; two denotes the existence of active movement; three means active movement against gravity; four indicates active movement against gravity and manual resistance; five is used for normal strength. Scott et al. ${ }^{9}$ defined the MRC index. In the present study, the indexes were also calculated, using the formula:

\section{$\operatorname{MRC}(\%)=$ Total muscle strength *100 \\ Number of tested muscles * 5}

The proximal upper limbs scores (involving shoulder flexors, extensors, abductors, adductors, internal and external rotators), the distal upper limbs scores (involving elbow flexors and extensors, supinators and pronator and wrist flexors and extensors), the proximal lower limbs scores (hip flexors, extensors, abductors, adductors, internal and external rotators) and the distal lower limbs scores (knee flexors and extensors and ankle dorsiflexors, plantar flexors, invertors and eversors) were calculated.

The Brazilian Portuguese version of MFM was used 5 . The scale includes 32 items, subdivided into three dimensions. Dimension 1 assesses the standing position and transfers (13 items); Dimension 2 assesses the axial and proximal limb motor function (12 items); and Dimension 3 tests distal limb motor function (7 items, 6 of which involving the upper limbs). Each item is scored from zero to three. Percentages are used to represent the scores on each Dimension and the total score.

\section{Data analysis}

Correlation analyses tested the relationships between motor function (MFM, Dimensions 1, 2 and 3 and total score) and muscle strength (MRC upper and lower limbs proximal score, MRC upper and lower limbs distal score and MRC total score). The possibility of relationship between these variables and age was also investigated.

As MFM provided ordinal variables and data displayed non-normal distribution, Spearman tests were used (Statistica 12.0). Significance level was set at alfa $\leq 0.05)$. Correlations were considered strong when $r \geq 0.80$ and moderate when 0.40 $\leq \mathrm{r} \leq 0.79$.

\section{RESULTS}

Age ranged from 12 to 30 (median 18), Vignos ranged from 7 to 9 (median 7). Table shows Spearman correlation coefficients obtained by correlating MRC total and partial scores (muscle strength) to MFM total and partial scores (motor function). The total scores of muscle strength and motor function were strongly correlated $(r=0.94 ; p<0.001)$, but not to age $(r=-0.19 ; p=0.831$ and $\mathrm{r}=-0.31 ; \mathrm{p}=0.102$, respectively). Patients with higher muscle strength scores also showed higher motor function scores (Table). Muscle strength and motor function showed moderate to strong relationships to each other, but not to age.

\section{DISCUSSION}

In the present study we found moderate to strong relationships between motor function and muscle strength in a sample of 40 patients with DMD. However, motor function and muscle strength were not related to age. This means that a considerable variability of muscle strength and motor function can be observed among different ages.

Benaïm et al. ${ }^{18}$ investigated the correlation between muscle strength and motor function, using MRC and MFM, respectively. Patients aged 18-78 years, with neuromuscular diseases, e.g. myotonic dystrophy and facioscapulohumeral dystrophy were assessed. The total and partial scores of MFM were correlated to MRC total score and partial indexes. The authors considered MRC useful to provide more specific data and to complement MFM. However, the study did not provide specific data about patients with $\mathrm{DMD}$, and focused on neuromuscular diseases in general.

In 2012, Diniz et al. ${ }^{19}$ investigated the muscle strength and motor function of 20 patients with DMD. They found moderate to strong correlations between MRC scores and all Dimensions of MFM. However, they assessed only the muscle strength of shoulders, elbows, wrists, hips, knees and ankles flexors and extensors. Therefore, we believe that the present study amplifies the data and discussion of Diniz et al. ${ }^{19}$, because we evaluated a higher number of muscle groups and a higher sample.

Table. Relationship between muscle strength Medical Research Council (MRC) scale, Motor Function Measure (MFM) and age (years): Spearman correlation coefficients ( $r$ ).

\begin{tabular}{|c|c|c|c|c|c|}
\hline \multirow{2}{*}{ Variables } & \multicolumn{4}{|c|}{ MFM } & \multirow{2}{*}{ Age } \\
\hline & Total score & Dimension1 & Dimension2 & Dimension3 & \\
\hline Total muscle strength & $0.94 * \star$ & $0.62^{\star}$ & $0.92 * \star$ & $0.87 * *$ & -0.19 \\
\hline Upper limbs proximal muscle strength & $0.92^{\star *}$ & $0.55^{\star}$ & $0.90 * *$ & $0.85^{\star *}$ & -0.35 \\
\hline Lower limbs proximal muscle strength & $0.76^{*}$ & $0.53 *$ & $0.79 *$ & $0.69 *$ & -0.11 \\
\hline Upper limbs distal muscle strength & $0.89 * *$ & $0.60 *$ & $0.85^{\star *}$ & $0.88^{* *}$ & -0.20 \\
\hline Lower limbs distal muscle strength & $0.79 *$ & $0.60 *$ & $0.78^{*}$ & $0.77 *$ & -0.04 \\
\hline Age & -0.31 & -0.33 & -0.34 & -0.25 & - \\
\hline
\end{tabular}

Strong correlations are marked with ** and moderate correlations with *; $\mathrm{p} \leq 0.05$ for all marked (strong and moderate) correlation coefficients. MFM: Motor Function Measure. Medical Research Council formulas were used to calculate total and partial muscle strength scores. 
The strong relationships between muscle strength and motor function found in the present study differs from the studies of Beenakker et al. ${ }^{15}$ and Parreira et al. ${ }^{13}$ Beenakker et al. ${ }^{15}$ state that, during the progression of DMD, high functional changes can be associated to little deterioration of muscle strength. The differences found between the study of Beenakker et al. ${ }^{15}$ and ours can be attributed to the method of motor function and muscle strength assessment and sample characteristics. Beenakker et al. ${ }^{15}$ evaluated motor function with timed scores, which are highly variable in patients with $\mathrm{DMD}^{22,23}$ and muscle strength with dynamometry ${ }^{24}$, which allows the inclusion of only a reduced number of muscle groups. Besides, Beenakker et al. ${ }^{15}$ studied ambulatory patients (aged 5-8 yrs) and, in the present study, we included only non-ambulatory patients (aged 12-30 yrs). Therefore, the relationships between muscle strength and motor function can be different in ambulatory and non-ambulatory patients.

In 2010, Parreira et al. ${ }^{13}$ compared the progression of muscle strength (assessed by MRC) and motor function (evaluated by Hammersmith Motor Assessment Scale), of patients with DMD treated with the sample described by Scott et al. ${ }^{9}$, of non-treated patients. They concluded that, among patients treated with steroids, the progression of DMD was slower in all age groups evaluated. They also stated that muscle strength tended to be proportionally more compromised than motor function. This information is in disagreement with our findings, which show that muscle strength seems to be as compromised as motor function, because they are strongly related.

We found that the total muscle strength was strongly related to the total score of MFM $(r=0.94 ; p<0.001)$, Dimension $2(\mathrm{r}=0.92 ; \mathrm{p}<0.001)$ and Dimension 3 of MFM $(\mathrm{r}=0.87$; $\mathrm{p}<0.001)$. The performance on transferring and stabilizing the trunk, measured by Dimension 2 and the performance on distal motor tasks, measured by Dimension 3, were strongly related to the total muscle strength. This suggests that transferring capacity, trunk control and upper limbs dexterity can differentiate patients with DMD with Vignos 7-9 and vary proportionally to the global muscle strength condition. Conversely, the total muscle strength was moderately related to Dimension 1 of MFM ( $r=0.62 ; \mathrm{p}=0.021)$. The performance on standing and locomotion, measured by Dimension 1 , was compromised in most patients, which caused a floor effect in this section and resulted on a lower correlation coefficient.

It is interesting to note that the proximal upper limbs strength was not only related to Dimension 2 of MFM, which evaluates tasks involving trunk muscles $(r=0.90$; $\mathrm{p}<0.001)$, but also to the total score $(\mathrm{r}=0.92$; $\mathrm{p}<0.001)$ and to Dimension 3 of MFM, which involves distal motor control $(\mathrm{r}=0.85 ; \mathrm{p}<0.001)$ (Table). The upper limbs distal muscle strength was also strongly related to Dimensions 2 and 3 and to the total score of MFM $(r=0.85 ; r=0.88 ; r=0.89$, respectively; $\mathrm{p}<0.001$ for all coefficients) (Table). Therefore, better proximal strength on upper limbs resulted on better trunk and shoulders stability, also leading to better distal function.
Bartels et al. ${ }^{1}$ assessed the upper limbs of patients with DMD with Dimension 3, MRC, dynamometry and goniometry. They concluded that, although the preservation of muscle strength and range of motion influenced distal motor function, there was great variability in these three variables. Dimension 3 assesses distal motor function and is more related to the distal muscle strength of upper limbs. From seven tasks evaluated on this Dimension, six are related to upper limbs functions and only one to lower limbs functions (ankle plantar and dorsal flexion assessment). Diniz et al. ${ }^{19}$ found strong correlations between upper limbs distal muscle strength and Dimension $3(r=0.80 ; p=0.002)$. In the present study, we found even higher correlation $(r=0.88$; $p<0.001)$, although we tested the strength of a higher number of muscles and on a more homogeneous population (Vignos 7-9) ${ }^{20}$.

Considering the lower limbs strength, we found that the proximal and the distal strength were moderately related to the total score $(r=0.76$; $p<0.001$ and $r=0.79 ; p<0.001$, respectively) and to Dimension $3(\mathrm{r}=0.69 ; \mathrm{p}<0.001$ and $\mathrm{r}=0.77$; $\mathrm{p}<0.001$, respectively) (Table). We found moderate correlations between lower limbs proximal and distal strength and Dimension 1 ( $r=0.53, p=0.031 ; r=0.60 ; p=0.020$, respectively). Diniz et al. ${ }^{19}$ found a stronger correlation between the lower limbs proximal muscle strength and Dimension $1(r=0.90$, $\mathrm{p}<0.001$ ). They included patients with lower Vignos scores and higher functional performance. Therefore, some patients had better proximal lower limbs strength, which may have contributed to this higher relationship.

In the present study, lower limbs proximal strength was strongly related to Dimension $2(r=0.80 ; p<0.001)$ and moderately related to lower limbs distal strength $(r=0.78$; $\mathrm{p}=0.001$ ) (Table). Proximal and distal strength of lower limbs are fundamental to stabilize trunk and lower limbs when the patient is performing the transferring and trunk support tasks from Dimension 2.

Age was not correlated to muscle strength, nor to motor function (Table). This means that age cannot be used to infer muscle strength loss in DMD and should not be used to monitor these patients. The genetic heterogeneity in DMD can explain the clinical heterogeneity ${ }^{25}$. Age is not related to DMD milestones and should not be the only variable used to monitor DMD progression. Not only the losses of muscle strength and motor function, but also their consequences, such as fatigue and joints contractures, vary broadly among specific age groups of patients with $\mathrm{DMD}^{26,27}$.

Recent studies elaborated and applied functional scales to assess patients with DMD sitting and standing from a chair, using the Functional Evaluation Scale for DMD. They showed weak or no correlation between the scores on sitting on the chair $(r=0.44 ; p=0.018)$ and rising from the chair ( $r=0.05 ; \mathrm{p}=0.830)$ and age $^{28}$ and between the scores on climbing up ( $\mathrm{r}=0.59 ; \mathrm{p}=0.004)$ and climbing down steps $(r=0.50 ; p=0.005)$ and age ${ }^{29}$. The progression of DMD differed highly among patients ${ }^{28}$. 
The highest correlation coefficient found was between the total score of MFM and the total muscle strength index $(r=0.94, p<0.001)$. This high coefficient shows the importance of not focusing only on specific muscle groups, but considering the overall motor condition of the patient on decision-making involving motor function.

Many studies have used functional scales, instead of MRC, to assess patients with neuromuscular diseases, due to MRC subjectivity $11,12,13,14,15$. For instance, Vuillerot et al. ${ }^{30}$ showed that the MFM was useful to detect mobility loss and functional dependence increase. It predicted gait loss within a year, when Dimension 1 was $40 \%$ or lower ${ }^{30}$. Conversely, Bakker et al. ${ }^{26}$ showed that MRC provided good references for DMD prognosis. When hip extensors were classified as 2 or lower and when dorsiflexors were scored below 4 , there was higher risk of gait loss within two years.

Moreover, the present study found stronger relationships between muscle strength and MFM than previous studies ${ }^{13,15,18,19}$. This fact can be attributed to the extensive practice with patients with DMD of all the examiners that participated in this study. This may have eliminated the subjectivity of MRC, e.g. the amount of manual resistance applied to differ score 4 (moderate resistance) from 5 (strong resistance), because, with extensive practice, therapists become able to adjust the amount of manual resistance given to patients with severe weakness. For this reason, we observed that a more subjective scale, as MRC, was related to a more standardized, valid and reproducible scale, as the MFM ${ }^{11,12}$.

As we only included patients with Vignos 7-9, future studies should investigate the relationship of muscle strength and motor function in ambulatory patients. The present study evidenced moderate to strong correlations between muscle strength and motor function, evaluated by MRC and MFM, in non-ambulatory DMD patients. It is possible to infer that non-ambulatory patients with lower muscle strength will also show lower motor function.

\section{References}

1. Bartels B, Pangalila RF, Bergen MP, Cobben NAM, Stam HJ, Roebroeck ME. Upper limb function in adults with Duchenne muscular dystrophy. J Rehabil Med. 2011;43(9):770-5. doi:10.2340/16501977-0841

2. Vuillerot C, Payan C, Girardot F, Fermanian J, Iwaz J, Bérard C et al. Responsiveness of the motor function measure in neuromuscular diseases. Arch Phys Med Rehabil. 2012;93(12):2251-6.e1. doi:10.1016/j.apmr.2012.05.025

3. Servais L, Deconinck N, Moraux A, Benali M, Canal A, Van Parys F et al. Innovative methods to assess upper limb strength and function in non-ambulant Duchenne patients. Neuromuscul Disord. 2013;23(2):139-48. doi:10.1016/j.nmd.2012.10.022

4. Bérard C, Payan C, Hodgkinson I, Fermanian J. A motor function measure for neuromuscular diseases: construction and validation study. Neuromuscul Disord. 2005;15(7):463-70. doi:10.1016/j.nmd.2005.03.004

5. Iwabe C, Miranda-Pfeilsticker BH, Nucci A. Motor function measure: Portuguese version and reliability analysis. Rev Bras Fisioter. 2008;12(5):417-24. doi:10.1590/S1413-35552008000500012

6. McDonald CM, Henricson EK, Han JJ, Abresch RT, Nicorici A, Elfring GL et al. The 6-minute walk test as a new outcome measure in Duchenne muscular dystrophy. Muscle Nerve. 2010;41 (4):500-10. doi:10.1002/mus.21544

7. Mazzone E, Vasco G, Sormani MP, Torrente Y, Berardinelli A, Messina $S$ et al. Functional changes in Duchenne muscular dystrophy: 12-month longitudinal cohort study. Neurology. 2011;77(3):250-6. doi:10.1212/WNL.0b013e318225ab2e

8. Mazzone ES, Pane M, Sormani MP, Scalise R, Berardinelli A Messina S et al. 24 month longitudinal data in ambulant boys with Duchenne muscular dystrophy. PLoS One. 2013;8(1):e52512. doi:10.1371/journal.pone.0052512

9. Scott OM, Hyde SA, Goddard C, Dubowitz V. Quantification of muscle function in children: a prospective study in Duchenne muscular dystrophy. Muscle Nerve. 1982;5(4):291-301. doi:10.1002/mus.880050405

10. Florence JM, Pandya S, King WM, Robison JD, Baty J, Miller JP et al. Intrarater reliability of manual muscle test (Medical Research Council scale) grades in Duchenne's muscular dystrophy. Phys Ther. 1992;72(2):115-22.
11. Escolar DM, Henricson EK, MayheW J, Florence J, Leshner R, Patel $\mathrm{KM}$ et al. Clinical evaluator reliability for quantitative and manual muscle testing measures of strength in children. Muscle Nerve. 2002;24(6):787-93. doi:10.1002/mus.1070

12. Merlini L, Bertini E, Minetti C, Mongini T, Morandi L, Angelini C et al. Motor function-muscle strength relationship in spinal muscular atrophy. Muscle Nerve. 2004;29(4):548-52. doi:10.1002/mus.20018

13. Parreira SLS, Resende MBD, Zanoteli E, Carvalho MS, Marie SK, Reed UC. Comparison of motor strength and function in patients with Duchenne muscular dystrophy with or without steroid therapy. Arq Neuropsiquiatr. 2010;68(5):683-8. doi:10.1590/S0004-282X2010000500002

14. Scott OM, Mawson SJ. Measurement in Duchenne muscular dystrophy: considerations in the development of a neuromuscular assessment tool. Dev Med Child Neurol. 2006;48(6):540-4. doi:10.1017/S0012162206001137

15. Beenakker EAC, Maurits NM, Fock JM, Brouwer OF, Hoeven JH. Functional ability and muscle force in healthy children and ambulant Duchenne muscular dystrophy patients. Eur J Paediatr Neurol. 2005;9(6):387-93. doi:10.1016/j.ejpn.2005.06.004

16. Fischmann A, Hafner P, Gloor M, Schmid M, Klein A, Pohlman $U$ et al. Quantitative MRI and loss of free ambulation in Duchenne muscular dystrophy.J Neurol. 2013;260:969-74. doi:10.1007/s00415-012-6733-x

17. Jansen M, Alfen N, Geurts AC, Groot IJ. Assisted bicycle training delays functional deterioration in boys with Duchenne muscular dystrophy: the randomized controlled trial "no use is disuse". Neurorehabil Neural Repair. 2013;27(9):816-27. doi:10.1177/1545968313496326

18. Benaïm C, Sacconi S, Fournier-Mehouas M, Tanant V, Desnuelle C. [Validity of the motor function measurement scale when routinely used in the follow-up of adult outpatients in a neuromuscular center]. Rev Neurol (Paris). 2009;166(1):49-53. French.

19. Diniz GPC, Lasmar LM, Giannetti JG. Motor assessment in patients with Duchene muscular dystrophy. Arq Neuropsiquiatr. 2012;70(6):416-21. doi:10.1590/S0004-282X2012000600007

20. Vignos PJ Jr, Spencer GE, Archibald KC. Management of progressive muscular dystrophy in childhood. JAMA. 1963;184(2):89-96. doi:10.1001/jama.1963.03700150043007 
21. Bushby k, Finkel R, Birnkrant DJ, Case LE, Clemens PR, Cripe $L$ et al. Diagnosis and management of Duchenne muscular dystrophy, part 1: diagnosis, and pharmacological and psychosocial management. Lancet Neurol. 2010;9(1):77-93. doi:10.1016/S1474-4422(09)70271-6.

22. Martini J, Voos MC, Hukuda ME, Resende MBD, Caromano FA. Compensatory movements during functional activities in ambulatory children with Duchenne muscular dystrophy. Arq Neuropsiquiatr. 2014;72(1):5-11. doi:10.1590/0004-282X20130196

23. Martini J, Hukuda ME, Caromano FA, Favero FM, Fu C, Voos MC. The clinical relevance of timed motor performance in children with Duchenne muscular dystrophy. Physiother Theory Pract. 2015;31(3):173-81. doi:10.3109/09593985.2014.989294

24. Mattar FL, Sobreira C. Hand weakness in Duchenne muscular dystrophy and its relation to physical disability. Neuromuscul Disord. 2008;18(3):193-8. doi:10.1016/j.nmd.2007.11.004

25. Magri F, Govoni A, D’Angelo MG, Del Bo R, Ghezzi S, Sandra $\mathrm{G}$ et al. Genotype and phenotype characterization in a large dystrophinopathic cohort with extended follow-up.J Neurol. 2011;258(9):1610-23. doi:10.1007/s00415-011-5979-z
26. Bakker JP, De Groot IJ, Beelen A, Lankhorst GJ. Predictive factors of cessation of ambulation in patients with Duchenne muscular dystrophy. Am J Phys Med Rehabil. 2002;81(12):906-12 doi:10.1097/00002060-200212000-00004

27. Gaudreault N, Gravel D, Nadeau S, Houde S, Gagnon D. Gait patterns comparison of children with Duchenne muscular dystrophy to those of control subjects considering the effect of gait velocity. Gait Posture. 2010;32(3):342-7. doi: 10.1016/j.gaitpost.2010.06.003

28. Hukuda ME, Escorcio R, Fernades LA, Carvalho EV, Caromano FA. Evaluation scale development, reliability for sitting and standing from the chair for Duchenne muscular dystrophy. J Mot Behav. 2013:45(2):117-26. doi:10.1080/00222895.2012.760513

29. Fernandes LA, Caromano FA, Hukuda ME, Escorcio R, Carvalho EV. Elaboration and reliability of functional evaluation on going up and downstairs scale for Duchenne Muscular Dystrophy (DMD). Rev Bras Fisioter. 2010;14(6):518-26. doi:10.1590/S1413-35552010000600011

30. Vuillerot C, Girardot F, Payan C, Fermanian J, Iwaz J, De Lattre C et al. Monitoring changes and predicting loss of ambulation in Duchenne muscular dystrophy with Motor Function Measure. Dev Med Child Neurol. 2010;52(1):60-5. doi:10.1111/j.1469-8749.2009.03316.x 